\title{
Escalas do urbano e o alcance de "pequenas" mobilizações sociais: O Março das Mulheres em Santarém (PA)
}

Telma de Sousa Bemerguy

\section{(2) OpenEdition}

Journals

Edição electrónica

URL: http://journals.openedition.org/aa/3342

DOI: $10.4000 /$ aa.3342

ISSN: 2357-738X

Editora

Programa de Pós-Graduação em Antropologia Social (UnB)

Edição impressa

Data de publição: 1 dezembro 2018

Paginação: 361-368

ISSN: 0102-4302

Refêrencia eletrónica

Telma de Sousa Bemerguy, «Escalas do urbano e o alcance de "pequenas" mobilizações sociais: 0 Março das Mulheres em Santarém (PA)», Anuário Antropológico [Online], v.43 n.2 | 2018, posto online no dia 26 maio 2019, consultado o 28 abril 2021. URL: http://journals.openedition.org/aa/3342 ; DOI: https://doi.org/10.4000/aa.3342

\section{(c) $)(1)(9)$}

Anuário Antropológico is licensed under a Creative Commons Atribuição-Uso Não-Comercial-Proibição de realização de Obras Derivadas 4.0 International. 


\title{
Escalas do urbano e o alcance de "pequenas" mobilizações sociais: O Março das Mulheres em Santarém (PA) ${ }^{1}$
}

\author{
Telma de Sousa Bemerguy \\ PPGAS/Museu Nacional \\ tsbemerguy@gmail.com
}

No dia 8 de março de 2018, milhares de mulheres foram às ruas em todo o Brasil para defender pautas relacionadas à luta pela igualdade de gênero. A grandiosidade das marchas realizadas nas metrópoles do país, compostas por uma multidão de mulheres, trios elétricos, bandeiras gigantescas e faixas incontáveis, compõe o principal referente imagético relacionado aos atos do Dia Internacional da Mulher $(8 \mathrm{M})$. Nesse ensaio, exploro outras proporções de mobilizações sociais urbanas e apresento registros do Ato $8 \mathrm{M}$ realizado em Santarém, um município de aproximadamente 300 mil habitantes, localizado no Estado do Pará. Exponho imagens de um ato público onde apenas um microfone e um megafone passavam de mão em mão, de registros de uma marcha animada por dois instrumentos de percussão, um pequeno carro de som e pelas vozes de cerca de cinquenta mulheres em sua luta "contra os poderosos de todo o mundo".

No contexto amazônico, o processo de formação das cidades primeiramente se deu a partir de ações de colonização conduzidas em áreas estratégias às margens dos rios. Nesse sentido, o núcleo populacional que deu origem à cidade Santarém foi fruto de ações da colonização portuguesa, realizadas às margens de dois rios, o Tapajós (águas claras) e o Amazonas (águas barrentas), que se encontram sem se misturar na "frente da cidade". Ali, em uma praça na beira do rio, exatamente onde os colonizadores construíram a igreja matriz, mulheres ligadas a diversos movimentos sociais e coletivos políticos locais se reuniram para a concentração desse Ato $8 \mathrm{M}$. Em 2018, pela primeira vez, essas mulheres decidiram se reunir para organizar uma programação única de debates e atos públicos relacionados à data. A marcha foi o evento de encerramento do Março das Mulheres, uma semana de atividades resultante da parceria entre os coletivos.

Nas imagens que seguem, privilegiei tons e cores que destacam a paisagem de beira de rio da cidade, registros que situam o número de pessoas presentes no ato 
e enquadramentos baixos que, através da fotografia, me permitiram fazer crescer o tamanho da manifestação, produzindo uma metáfora do alcance de atos de ocupação do espaço público em contextos urbanos de menor escala. Assim, busquei produzir um contraponto ao referente imagético da grande manifestação e aos ideários associados ao fenômeno urbano, tencionando os limites de definições ordinárias que não raramente associam o urbano à paisagem das metrópoles e os efeitos da ação política ao número de presentes nos atos públicos.

O início do movimento de mulheres na cidade remonta aos anos 80 , quando foi criada a Associação das Mulheres Domésticas de Santarém. Na década de 90, o trabalho de mobilização realizado por essas primeiras mulheres cresceu e resultou na criação da Associação de Mulheres Trabalhadoras do Baixo Amazonas, o que possibilitou o fortalecimento do debate sobre a experiência das mulheres em sindicatos urbanos e rurais da região. Atos de militância significados como feministas, no entanto, começaram a ganhar força e protagonismo na cidade, mais recentemente, a partir dos efeitos da ampliação do acesso ao ensino superior em Santarém, com a criação da Universidade Federal do Oeste do Pará (UFOPA), em 2011. Grande parte dos coletivos que integraram a organização do Março das Mulheres surgiu nesse contexto. Nesse sentido, destaco que a grande diferença geracional entre as mulheres presentes na marcha reflete a história dos movimentos de mulheres na cidade.

Sendo natural de Santarém e egressa da UFOPA, ao longo da graduação em Antropologia, pude ter experiências de convívio e militância no movimento estudantil junto a algumas das mulheres que hoje se tornaram lideranças importantes na região. Esse ensaio, portanto, é fruto de uma inserção etnográfica marcada pelas minhas vivências como uma mulher da Amazônia. Desde esse lugar, acompanhei as atividades da semana, fotografei o ato e conduzi as conversas e entrevistas que possibilitaram a produção desse trabalho. As reflexões apresentadas, por sua vez, são fruto de um investimento analítico sobre a relação entre gênero, processos coloniais e representações sobre o território amazônico, interesses de pesquisa que compõem meu trabalho de doutorado.

Recebido: 25/05/2018

Aprovado: 17/11/2018 
Telma de Sousa Bemerguy 363

A concentração para a Marcha estava marcada para às $17 \mathrm{~h}$. O sol ainda estava forte quando algumas das organizadoras começaram a chegar. Ao longo das atividades da semana, a faixa lilás estendida no chão se tornou o símbolo do evento que reuniu diversos coletivos de mulheres da cidade de Santarém em torno de uma iniciativa única, o Março das Mulheres. Quando o sol começou a baixar, grande parte do público que participaria do evento já estava presente. Reunidos na simbólica Praça da Igreja Matriz, mulheres, homens e crianças interagiam enquanto aguardavam o início da marcha. O tamanho do ato pode ser observado tanto pelo número de pessoas presentes quando pela repetição de rostos, camisetas e faixas com temas correlatos ao longo dos registros.

Ao longo da marcha, as mulheres revezavam-se no megafone e no microfone. O som do batuque de dois pequenos instrumentos de percussão também estava ali para fazer ouvir a manifestação. As palavras de ordem enunciadas eram repetidas com toda força possível. Grande parte das presentes carregava um cartaz escrito à mão, produzido com material fornecido pela organização.
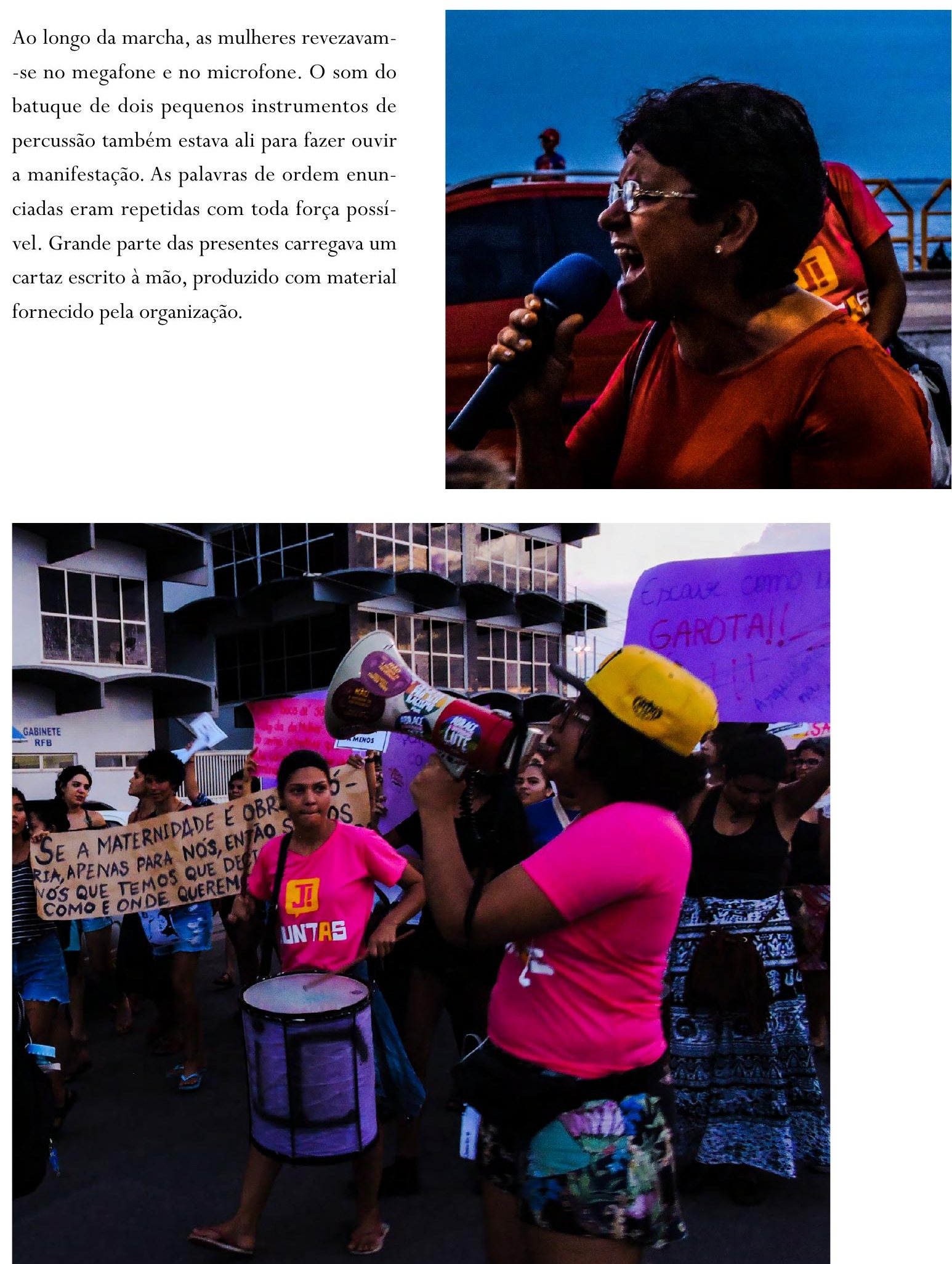


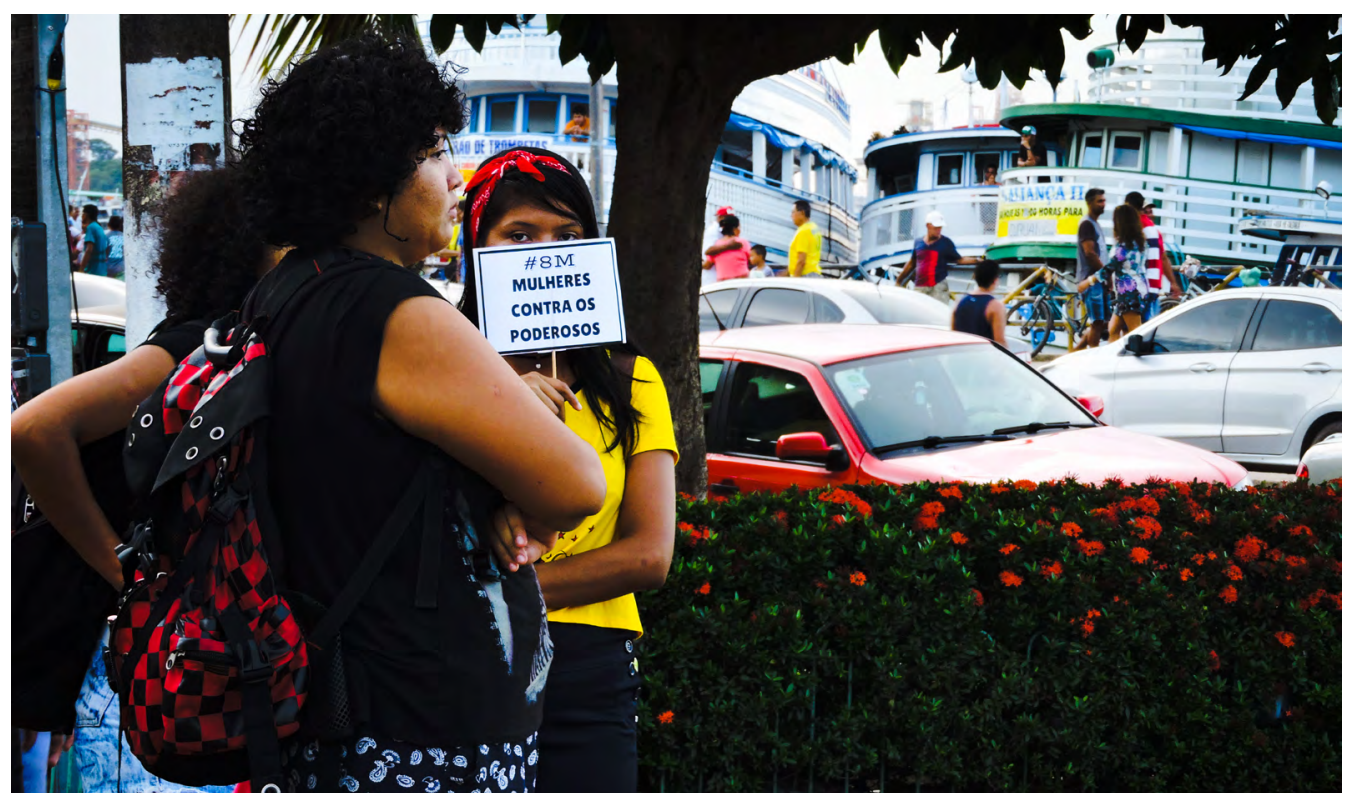

Em um ato produzido pela parceria entre mulheres de diferentes gerações, por mulheres mães, mulheres indígenas, mulheres quilombolas, mulheres negras, por trabalhadoras urbanas e rurais, por mulheres heterossexuais, bissexuais e lésbicas ligadas a movimentos sociais que militavam por pautas específicas das mais diversas, a referência aos "poderosos de todo o mundo" remete a uma luta comum. Se por um lado, a abrangência da expressão se contrapõe ao tamanho físico da manifestação, por outro se torna reveladora do "tamanho" que pode alcançar um ato público como esse em cidades de menor porte.

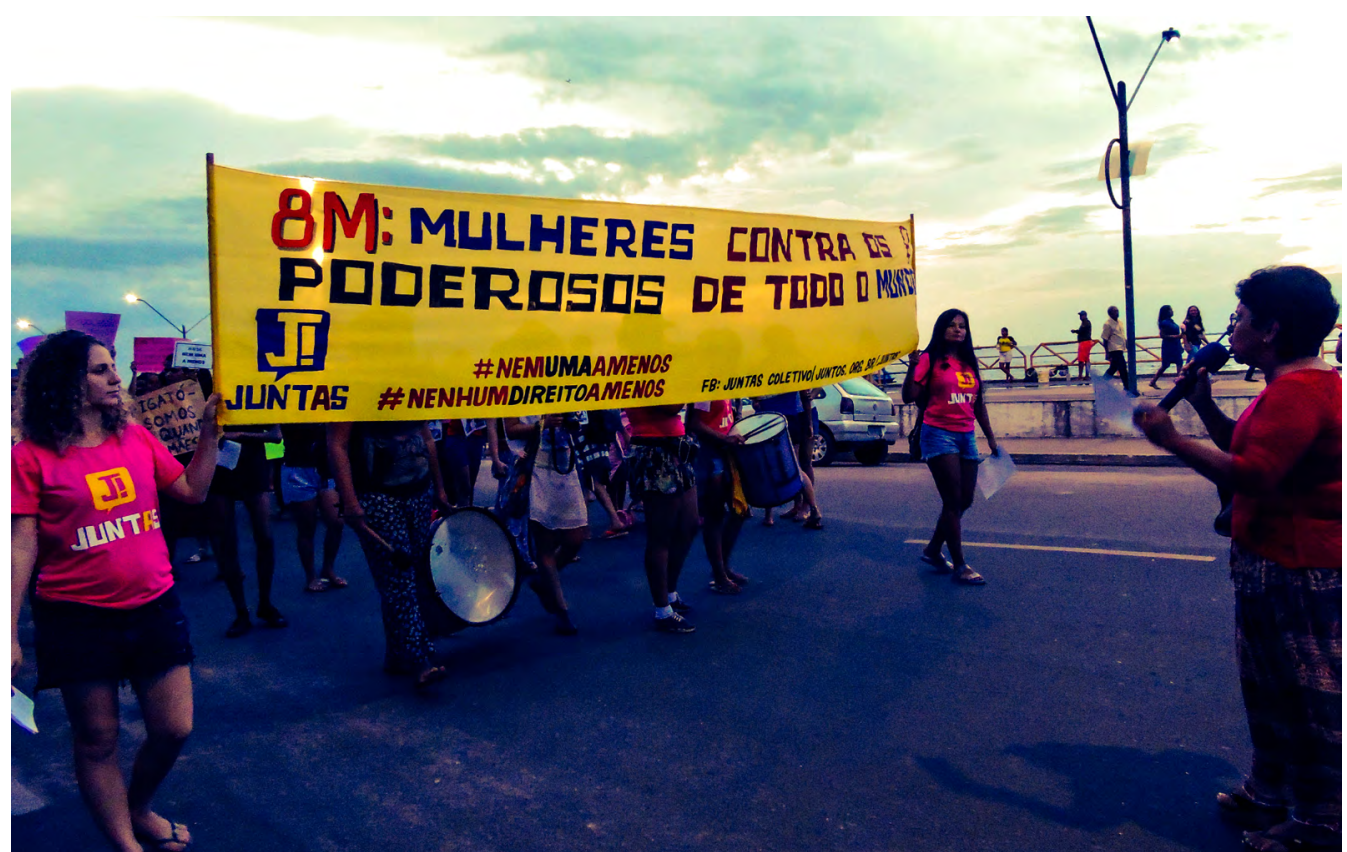




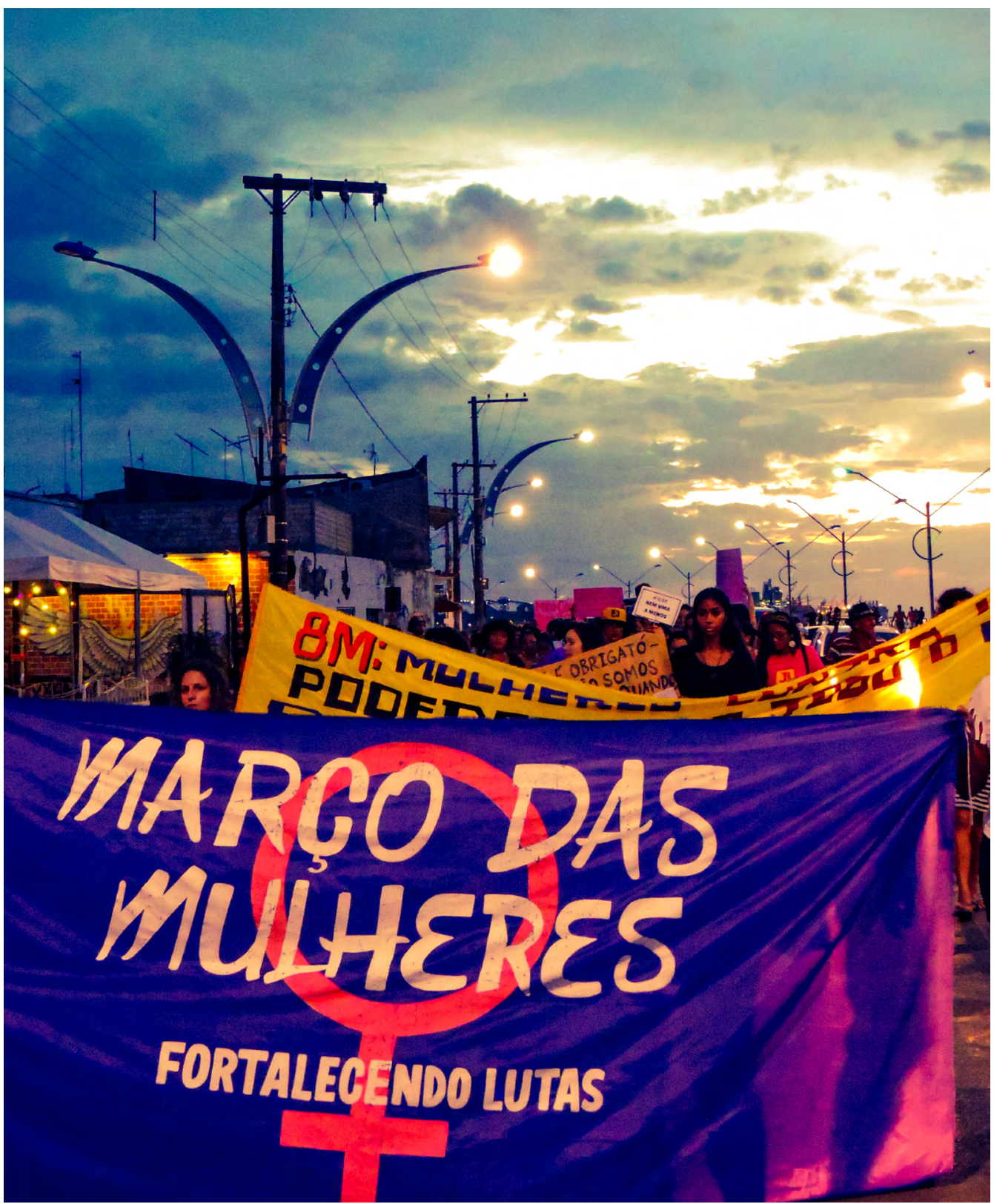

Em cidades de colonização histórica como Santarém, os rios ocupam um lugar central na composição do urbano e na dinâmica dos trânsitos e trocas estabelecidos com localidades, municípios e estados vizinhos. A ocupação estratégica da orla ampliou o ato na dimensão de seu alcance e reverberação, fazendo com que a mobilização crescesse para além de Santarém e com que o "tamanho" da Marcha se borrasse. 
Nessa mobilização, o exercício da ação política é caracterizado por uma maior pessoalidade, de modo que os efeitos da menor escala e da interação face-a-face se encontram tanto no nível dos desafios particulares enfrentados por esse grupo pequeno e diverso em organizar atividades em conjunto, quanto na dimensão das trocas possibilitadas por uma marcha em que os participantes podem interagir em roda.

Crédito das imagens: Telma Bemerguy, Santarém (PA), 2018.

\section{Notas}

1. Esse ensaio é fruto de trabalho de campo financiado com fundos do Edital 2017 de Auxílio à Pesquisa do PPGAS/Museu Nacional. Em nome de Tati Picanço e Luanna Silva, agradeço às organizadoras do evento pela interlocução. 